\title{
IDENTIFIKASI PROBLEMATIKA BUMDES DI DESA-DESA DI KECAMATAN LINGSAR LOMBOK BARAT
}

\author{
Biana Adha Inapty \\ Universitas Mataram \\ bianainapty@hotmail.com \\ M. Ali Fikri \\ Universitas Mataram \\ fikri.sampala@unram.ac.id \\ Iman Waskito \\ Universitas Mataram \\ waskitoiman@unram.ac.id \\ Disubmit : 15 Februari 2021 \\ Direview : 3 Oktober 2021 \\ Diterima : 16 Desember 2021
}

\begin{abstract}
As we know, the government has disbursed Village Funds (Dana Desa, DD) and Village Fund Allocations (Anggaran Dana Desa, ADD) in order to build independent villages. Based on this fact, our research tries to identify problems that occur in the field. The findings targeted in this research are the revealing of problems based on the phenomena that occur Methodology of this research is qualitative research with district facilitators, village heads, BUMDES managers, and local village assistants as respondents. The results show that the problems that are still faced by BUMDES are the small percentage of capital participation by villages to BUMDES which ranging from 1-2\% a year, human resources, bookkeeping, cooperation has not been widely carried out with outside parties, products from the community have not been accommodated by BUMDES, much of villagepotential has not been explored and developed.
\end{abstract}

Keywords: Village, Village Funds, and BUMDES, Problematic

\begin{abstract}
Abstrak
Sebagaimana kita ketahui pemerintah telah menggelontorkan dana desa (DD) dan alokasi dana desa (ADD) dalam rangka membangun desa yang mandiri. Berangkat dari hal tersebut penelitian ini berupaya mengidentifikasi masalah yang terjadi dilapangan. Temuan yang ditargetkan dalam penelitian ini terungkapnya problematikaberdasarkan fenomena yang terjadi.Metodologi penelitian ini menggunakan kualitatif dengan responden fasilitator kabupaten, kepala desa, pengelola bumdes, pendamping lokal desa.Hasil penelitian menunjukkan problematikayang masih dihadapi oleh Bumdes adalah mengenai kecilnya persentase penyertaan modal oleh desa ke Bumdes berkisar 1-2\% setahun, sumber daya manusia, pembukuan, kerjasama belum banyak dilakukan dengan pihak luar, produk dari masyarakat belum ditampung oleh Bumdes, potensi desa banyak yang belum digali dan dikembangkan.
\end{abstract}

Kata Kunci: Desa; Dana desa; Bumdes; Problematika. 


\section{PENDAHULUAN}

Dalam Pasal 1 Angka (6) Undang - Undang Nomor 6 Tahun 2014 tentang Desa, secara definisi Badan Usaha Milik Desa yang selanjutnya disebut BUM Desa adalah badan usaha yang seluruh atau sebagian besar modalnya dimiliki oleh desa melalui penyertaan secara langsung yang berasal dari kekayaan yang dipisahkan guna mengelola aset, jasa pelayanan dan usaha lainnya untuk sebesar-besarnya bagi kesejahteraan masyarakat desa.Perkembangan jumlah Bumdes di Indonesia tergolong sangat pesat. Menurut Kementrian Desa, pembangunan Daerah tertinggal dan Transmigrasi (Kemendes PDT) pada November 2018 jumlah Bumdes diIndonesia mencapai 41.000 unit tersebar di 74.957 desa namun Bumdes yang terbentuk sebagian besar tersebar di Indonesia bagian Barat. Sedang di Indonesia bagian timur masih minim meski potensi daerahnya tidak kalah potensial. Perkembangan Bumdes menjadi 6 kali lipat dari target RPJMN maupun target Kemendesa yang hanya mematok 5000 BUMDES. (https://republika.co.id/).

Pertanyaannyakemudian adalah apakah BUMDes sudah siap menjadi kekuatan ekonomi di Indonesia?. Problematikayang ada adalah banyak data yang menyebutkan bahwa sebagian besar BUMDes sebatas berdiri dan belum memiliki aktivitas usaha yang menghasilkan. Sebagian malah layu sebelum berkembang karena masih sedikitnya pemahaman BUMDes pada sebagian besar kepala desa (https://kontan.co.id). Penyeleggaraan pembentukan Bumdes begitu massif dilakukan dan diketahui bahwa hingga tahun 2017 lebih dari 22.000 desa telah memiliki Bumdes, namun Bumdes yang aktif berkegiatan kurang dari 20\% (Suryanto, 2018 dalam Hidayah, dkk 2019). Di Provinsi NTB sendiri menurut data yang direleaseSatker Direktorat PUED Kemendes PDTT pada tahun 2015, dari jumlah Desa sebanyak 995, desa yang memiliki bumdes sebanyak 420, dengan jumlah Bumdes yang aktif sebanyak 224, jumlah Bumdes yang kurang aktif sebnyak 67, jumlah Bumdes tidak aktif sebanyak 83, dan jumah Bumdes yang baru dibentuk sebanyak 45 .

Bumdes yang merupakan unit usaha dan revenue generating bagi Desa tentu harus memiliki ciri khas dan keunggulan kompetitif agar dapat memberikan kontribusi yang signifikan pada peningkatan kesejahteraan masyarakat desa. Pada teori resource based view, keunggulan kompetitif ditentukan oleh modal sosial, modal manusia, dan modal finansial (DeMassis et al., 2011). Modal sosial terkait dengan relasi antar orang dalam organisasi (modal sosial internal) dan antara organisasi dengan pihak luar (modal sosial). Menurut World Bank (1998), sosial capital adalah " $a$ society includes the institutions, the relatioships, the attitudes and values that govern interactions among people and contribute to economic and social development". Dalam sosial capital dibuthkan adanya "nilai saling berbagi" (shared values) serta pengorganisasian peran-peran (rules) yang diekspresikan dalam hubungan - hubungan personal (personal relationship), kepercayaan (trust), dan common sense tentang tanggung jawab bersama, sehingga masyarakat menjadi lebih dari sekedar kumpulan individu belaka. Selain modal sosial, modal yang menentukan keunggulan kompetitif dari organisasi. Modal manusia diartikan sebagai pengetahuan dan ketrampilan yang melekat pada orang (Hatch et al, 2004 dalam DeMassis et al., 2001). Modal manusia dapat diasosiasikan dengan dedikasi dan komitmen yang tinggi (Suarez et al., 2001), motivasi, dan relasi personal yang tinggi (Rodriguezet al, 2006).Penelitian ini mencoba menganalisis masalah menggunakan pendekatan teori resource based view karena pengembangan Bumdes memerlukan keunggulan kompetitif agar pengelolaan Bumdes menjadi lebih baik. Dalam mengembangkan Bumdes tak lepas dari keterlibatan berbagai pihak. Dalam stakeholder theory,pemangku kepentingan adalah individu atau kelompok yang dapat berpengaruh pada pencapaian tujuan organisasi, atau pihak yang terkena dampak dari pencapaian tujuan organisasi (Freeman et al., 1983 dalam Mitchell et al., 1997). Pemangku kepentingan memiliki beberapa atribut yaitu kekuasaan (power), legitimasi, dan urgensi. Penelitian ini menggunakan stakeholder theory karena untuk mengelola dan 
mengembangkan Bumdes membutuhkan perhatian dari para pemangku kepentigan yang memiliki power, legitimasi dan urgensi agar Bumdes menjadi lebih baik dan sesuai dengan tujuan yang diharapkan.

Penelitian mengenai identifikasi problematikaBumdes telah dilakukan oleh Kusuma dan Purnamasari (2016), menunjukkan permasalahan Bumdes terkait masalah komunikasi; akses masyarakat; transparansi dan akuntabilitas; kapasitas manajerial; infrastruktur, kebersihan, dan optimalisasi sarana; akses terhadap air; legal standing.Mayu dan Aldin (2016)menemukan Faktor-faktor penghambatnya terkait dengan masalah kepemimpinan, manajerial, tata kelola pemerintah desa, hal ini disebabkan karena kurangnya kualitas dan kapasitas pengetahuan yang dimiliki seorang pengelola Bumdes serta terbatasnya SDM yang ada dan pengetahuan pengurus sehingga menyebabkan kurang berkembangnya Bumdes Desa Tebih Mandiri.

Hastowiyono (2014)mengemukakan persoalan yang paling serius dalam Bumdes adalah kualitas dan kapasitas direktur, tradisi berdesa, ketidakpahaman warga terhadap Bumdes, pemilihan unit usaha yang tidak tepat, pembentukan kepengurusan, kelembagaan, pengelolaan, keterlibatan para pemangku kepentingan (stakeholder). Ketokohan seseorang yang terpilih menjadi direktur Bumdes tidak serta merta menjamin adanya kapasits kewirausahaan. ProblematikaBumdes juga dibahas pada studi yang dilakukan Aksa (2013) dalam Mayu dan Aldin (2016). Hasilnya, yaituproblematika- problematikaBumdes muncul karena adanya misscomunication antar pengurus Bumdes terkait administrasi keuangan, skala dan jangkauan usaha yang rentan untuk gulung tikar, emansipasi local, tidak adanya jalinan kerjasama antar Bumdes akan menjadi factor penghambat, tradisi berdesa (solidaritas, kerjasama,) yang tidak tercipta akan menghambat tumbuh dan berkembangnya Bumdes. Karlina dan Yudiardi (2017) serta Sumaryadi \& Saputra (2017) mengungjapkan bahwa factor utama yang menghambat Bumdes adalah kualitas sumber daya manusia. Faktor lainnya adalah kesalahan dalam identifikasi potensi dan oemilihan jenis usaha, kurangnya kesiapan dan kemampuan SDM dalam tata administrasi dan pembuatan laporan pertanggungjawaban, alokasi modal Bumdes yang kecil dari dana desa serta kurangnya evaluasi kinerja dan audit laporan keuangan (Syncore, 2017 dalam Prayogo \& Riswandari (2018). Temuan dari hasil - hasil penelitian terdahulu menunjukkan masih beragamnya permasalahan Bumdes. Penelitian identifikasi problematika Bumdes yang akan di lakukan di Kecamatan Lingsar belum pernah diteliti sebelumnyasehingga ini merupakan research awal. Dengan demikian kebaharuan dari penelitian ini terletak dari aspek lokasi. Penelitian ini bertujuan untuk mengidentifikasi problematika yang terjadi pada Bumdes-Bumdes di Desa-Desa di Kecamatan Lingsar Lombok Barat.Berdasarkan pleriminary survey yang dilakukan peneliti didapatkan informasi awal dari fasilitator Kabupaten Lombok Barat bahwa desa-desa kurang memberikan perhatian terhadap Bumdes dan ada semacam ketakutan akan mengalamikegagalan bila usaha tidak berhasil.Berdasarkan penjelasan diatas sehingga memotivasi untuk dilakukannya penelitian ini.

\section{METODE PENELITIAN}

Jenis penelitian ini adalah penelitian kualitatif. Moleong (2006) mendefinisikan penelitian kualitatif adalah penelitian yang bermaksud untuk memahami fenomena tentang apa yang dialami oleh subjek penelitian misalnya perilaku, presepsi, motivasi, tindakan dan lainlain secara holistic dan dengan cara deskriptif dalam bentuk kata-kata dan bahasa, pada suatu konteks khusus yang alamiah dan dengan memanfaatkan berbagai metode alamiah. Penelitian ini dilaksanakan pada Bumdes di desa - desa di Kecamatan Lingsar.

Kajian penelitian ini adalah bersifat deskriptif kualitatif.Bumdes di Kecamatan Lingsar yang telah terbentuk banyak yang tidak aktif kalaupun statusnya aktif Bumdes belum 
berkembang dengan baik, padahal sebagaimana kita ketahui desa-desa telah mendapatkan Dana Desa dan Alokasi Dana Desa sehingga jika pengembangan tidak dilakukan maka hal tesebut menjadi suatu yang riskan. Penelitian ini menggunakan data primer dan sekunder melalui teknik observasi, wawancara dan studi kepustakaan.Data selanjutnya dianalisis menggunakan pendekatan "fenomenologi deontologi" yang bertujuan menyingkapi fenomena yang terjadi dengan ikut menyertakan nilai-nilai alturisme untuk menganalisis peristiwa tersebut (Sanders, 1982, Etzioni, 1992 dan Fikri, 2010). Informan dalam penelitian in adalah pengelola Bumdes.

\section{HASIL DAN PEMBAHASAN}

Berdasarkan hasil wawancara dengan informan maka permasalahanproblematikaBumdes yang terjadi di Desa di kecamatan Lingsar berkaitan dengan problematikasumber daya manusia yaitu kapasitas manajerialnya yang masih kurang baik; problematikaregulasi; transparansi terhadap pengelolaan keuangan Bumdes yang tidak jelas sehingga penelitian ini sejalan dnegan penelitian Inapty (2019); Kusuma dan Purnamasari (2016); Mayu dan Aldin (2016); Karlina dan Yudiardi (2017) serta Sumaryadi \& Saputra (2017). Menurut Mayu dan Aldin (2016), factor-faktor penghambatnya tumbuh dan berkembangnya Bumdes di Desa Pematang Tebih Kec. Ujung Batu Kab. Rokan Hulu terkait dengan masalah kepemimpinan, manajerial, tata kelola pemerintah desa, hal ini disebabkan karena kurangnya kualitas dan kapasitas pengetahuan yang dimiliki seorang pengelola Bumdes serta terbatasnya sumber daya manusia yang ada dan pengetahuan pengurus sehingga menyebabkan kurang berkembangnya Bumdes Desa Tebih Mandiri.

Selain itu problematika Bumdes yang diidentifikasi lainnya di Kecamatan Lingsaradalah persentase yang kecil dari penyertaan modal pemerintah desa kepada Bumdes seperti yang diungkapka fasilitator kabupaten dimana berkisar 1-2 \% dari dana desa; kurangnya evaluasi oleh pemerintah desa, pemahaman masyarakat mengenai Bumdes yang kurang baik, kemudian kepengurusan dan pengelolaan yang tidak optimal, pemilihan usaha yang dirasa kurang tepat hal ini sejalan dengan penelitian yang dilakukan oleh Karlina dan Yudiardi (2017) serta Sumaryadi \& Saputra (2017) serta pendapat Hastowiyono (2014) yang mengemukakan bahwa persoalan yang paling serius dalam Bumdes adalah kualitas dan kapasitas direktur, tradisi berdesa, ketidakpahaman warga terhadap Bumdes, pemilihan unit usaha yang tidak tepat, pembentukan kepengurusan, kelembagaan, pengelolaan, keterlibatan para pemangku kepentingan (stakeholder). Yang yang diungkapkan diatas tiak jauh berbeda dengan yang dialami di Bumdes Karang Bayan sebagaimana yang diungkap oleh Ibu Nuaraeni

"seperti yang disebutkan tadi, orang yang mengelola juga masih kurang, selama ini kan saya sendiri lah gitu, yang lain tidak berfungsi. Dan juga permodalan, harusnya desa berani misalnya membentuk unit usaha lain terus dikasih modal, kalau desa-desa lain yang sudah maju yang besar-besar karena mereka berani menanam modal lebih besar sampi 50 juta, 100 juta. Kalau disini Cuma dibawah 10 juta tiap tahunnya itu, itu aja kan orang kurang. Itu yang membuat sulit berkembang."

Namun keadaan di Bumdes Mart Sigerongan berbeda dan lebih maju dari Bumdes Karang Bayan Mandiri, hal ini sebagaimana diungkap oleh Bapak Khairul Hadi

" Pada tahun 2016, yaitu pada saat awal dibentuknya Bumdes ini dialokasikan dana sebesar Rp 95.877.000. Pada tahun kedua yaitu tahun 2017 tidak ada alokasi dana dari desa tetapi ada bantuan dari Provinsi sebesar Rp 


\subsubsection{Pada tahun 2018 dan 2019 masing-masing dialokasikan sebesar} Rp 75.000.000”

Kemudian kurangnya kerjasama baik dengan Bumdes lain maupun kerjasama dengan pihak eksternal lainnya merupakan problematikayang dijumpai sebagaimana yang dikemukakan oleh DeMassis et al (2011) bahwa modal sosial terkait dengan relasi antar orang dalam organisasi (modal sosial internal) dan antara organisasi dengan pihak luar (modal sosial eksternal)dan diungkap juga pada penelitian yang dilakukan oleh Karlina dan Yudiardi (2017) serta Sumaryadi \& Saputra (2017) mengungkapkan bahwa factor utama yang menghambat Bumdes adalah kualitas sumber daya manusia. Problemtika terkait tidak adanya kerjasama dan kurangnya sumber aya manusia juga dialami baik di Bumdes Mart Sigerongan maupun Bumdes Karang Bayan Mandiri. Factor lainnya adalah kesalahan dalam identifikasi potensi dan pemilihan jenis usaha, kurangnya kesiapan dan kemampuan SDM dalam tata administrasi dan pembuatan laporan pertanggungjawaban, alokasi modal Bumdes yang kecil dari dana desa serta kurangnya evaluasi kinerja dan audit laporan keuangan (Syncore, 2017 dalam Prayogo \& Riswandari (2018). Problematikan terkait administrasi dan laporan pertanggungjawaban juga menjadi masalah klasik sebagaimana yang terjadi di Bumdes Mart Sigerongan dan Bumdes Karang Bayan, dimana untuk pencatatan masih dilakukan secara manual di Bumdes Karang Bayan sedangkan di Bumdes Mart sudah lebih maju dengan menggunakan Excel.

Saat ini desa-desa dikecamatan Lingsar masih menggali potensi desa yang dapat dikembangkan dan dijadikan usaha bagi Bumdes. Penggalian potensi usaha diharapkan dapat menjadi keunggulan kompetitif sehingga dapat memajukan desa. Potensi yang digali oleh beberapa desa di Kecamatan Lingsar untuk dapat dikembangkan sebagai desa wisata dll. Hal ini sesuai dengan yang dikemukakan oleh DeMassis et al, 2011 yang mengemukakan bahwa Unit-unit usaha yang bergerak di desa haruslah memiliki ciri khas dan keunggulan kompetitif agar dapat memberikan kontribusi yang signifikan pada peningkatan kesejahteraan masyarakat desa. Pada teori resource based view, maka keunggulan kompetitif ditentukan oleh modal sosial, modal manusia, dan modal finansial.

\section{SIMPULAN}

Hasil penelitian menunjukkan bahwa problematika bumdes masih diseputar problematika klasik yaitu, Pertama, Persentase Penyertaan modal oleh desa kepada Bumdes masih berkisar sekitar $1-2 \%$, hal ini disebabkan karena masih adanya kekuatiran pihak desa jika usaha yang dijalankan Bumdes tidak dapat berkembang. Kedua, Sumber daya manusia dimana masih banyak pengelola yang kurang serius dalam mengelola Bumdes disebabkan karena adanya pekerjaan lain atau juga karena banyak pengelola yang mencalonkan diri sebagai anggota dewan sehingga kegiatan dilakukan untuk kegiatan kampanye atau problematika pribadi lainnya. Sistem penggajian terhadap karyawan masih belum tertata dengan baik sehingga menurunkan motivasi karyawan dalam mengelola Bumdes. Ketiga, Kerjasama dengan pihak luar belum banyak dilakukan seperti dengan kalangan dunia usaha, pemerintah maupun dengan pihak akademisi atau Universitas.Berdasarkan hasil penelitian ini maka perlu dilakukan upaya-upaya perbaikan dalam mengatasi problematika Bumdes yaitu, Pertama, perlunya komitmen pimpinan yang kuat dalam mengelola Bumdes serta perlunya pemahaman kepala desa dari hulu ke hilir mengenai tata kelola desa, tata kelola keuangan, manajemen Bumdes; Kedua, perlunya penguatan SDM seperti mengintensifkan kegiatan Pendidikan \& pelatihan bagi pengelola Bumdes; perlunya sertifikasi bagi pengelola Bumdes terkait dengan kemampuan softskillnya; pendampingan \& pembinaan bagi Bumdes eecara berkelanjutan; Ketiga, perlunya 
peningkatan kerjasama dengan berbagai pihak demi kemajuan Bumdes melalui indikator kinerja dalam menilai Bumdes; dan Keempat, perlunya peningkatan dengan menggali potensi usaha di desa.

\section{DAFTAR PUSTAKA}

Asia Pacific Philantophy Consortium - APPC (2005). Developing Purposes Financial Accounting Standarts for NPO in Asia. Issues Paper, Bangkok.

Aksa, Sahrul (2013). "Kultur Jaringan BUMDes di Bantaeng”. www.academia.edu

Etzioni, Amitai. (1992), Dimensi Moral; Menuju Ilmu Ekonomi Baru. Edisi Terjemahan, Penerbit Remaja Rosdakarya Bandung.

Fikri, Ali (2010), "Studi Fenomenologi Akuntabilitas WWF (World Wide Fund for Nature)., Disertasi. Universitas Brawijaya. Malang.

Hastowiyono dan Suharyanto (2014). "Penyusunan Kelayakan Usaha dan Perencanaan Usaha BUM Desa. Forum pengembangan Pembaharuan Desa (FPPD) Yogyakarta". Seri Buku Pintar BUMDesa. Cetakan Pertama Januari 2014.

Hidayah U, Mulatsih S \& Purnaadewi L Y (2019) "Evaluasi Badan Usaha Milik Desa (Bumdes): Studi Kasus Bumdes Harapan Jaya Desa Pagelaran Keamatan Ciomas Kabupaten Bogor" Jurnal JSHP, Vol 3 No 2 Tahun 2019. P-ISSN 2580 - 5398, e-ISSN $2597-7342$

Kemendes: Jumlah Bumdes Mencapai 41 Ribu Unit, Red, Nidia Zuraya (https://republika.co.id/berita/ekonomi/korporasi/18/11/26/pissvc383-kemendes-jumlahbumdes-mencapai-41-ribu-unit )

Kusuma, Gabriella Hanny dan Purnamasari Nurul. (2016a). "Jurnal Penelitian Bumdes: Kewirausahaan Sosial Yang Berkelanjutan, Penabulu Jakarta. Accessed from http://jembatan.tiga.com/wp-content/uploads/BUMDes-Kewirausahaan-Sosial-yangBerkelanjutan.pdf"

Kusuma Hanny dan Purnamasari Nurul (2016b). “ Membangun Gerakan Desa Wirausaha ” Penabulu Foundation. Yogyakarta. Januari 2016

Mayu Indra Welli dan Adlin. "Faktor-Faktor yang Menghambat Tumbuh dan Berkembangnya Badan Usaha Milik Desa di Desa Pematang Tebih Kecamatan Ujung Batu Kabupaten Rokan Hulu Tahun 2014-2015". JOM FISIP Vol.3 No.2 Oktober 2016. Jurusan Ilmu Pemerintahan Fakultas Ilmu Sosial dan Ilmu Politik Universitas Riau

Mitchell, R.K., Agle, B.R and Wood, D.J. (1997). "Toward A Theory of Stakeholder Identification and Salience: Defining the Principle of Who and What Really Counts, Academy of Management Review, 22(4). 853-886".

Moleong, J, Lexy. (2006). "Metodologi Penelitian Kualitatif" Bandung. PT.Remaja. Rosdakarya

Peraturan Pemerintah Nomor 43 Tahun 2014 tentang Desa

Peraturan Menteri Dalam Negeri Nomor 39 Tahun 2010 tentang Badan Usaha Milik Desa

Peraturan Menteri Desa, Pembangunan Daerah tertinggal, dan Transmigrasi Republik Indonesia Nomor 2 Tahun 2015 Tentang Pedoman Tata Tertib dan Mekanisme Pengambilan Keputusan Musyawarah Desa

Pusat Kajian Dinamika Sistem Pembangunan. (2007). Buku Panduan Pendirian dan Pengelolaan BUM Desa Malang. Departemen Pendidikan Nasional (2007: 4 - 5).

Peraturan pemerintah No 47 Tahun 2015 tentang Perubahan Atas PP Nomor 43 Tahun 2014 tentang Peraturan Pelaksanaan UU Nomor 6 Tahun 2014 tentang Desa 
Peraturan Menteri Desa, Pembangunan Daerah Tertinggal, dan Transmigrasi Republik Indonesia Nomor 4 Tahun 2015 tentang Pendirian, Pengurusan dan Pengelolaan, dan Pembubaran Badan Usaha Milik Desa

Permendesa No 19 tahun 2017 tentang Prioritas Penggunaan Dana Desa 2018

PUED (2015), "Rekapitulasi Bumdes di Provinsi Nusa Tenggara Barat"

"Revitalisasi Bumdes Menteri Desa Targetka Kinerja Bumdes Bangkit Tahun Depan" Abdul Basith Bardan 8 Juli 2020, https://kontan.co.id

http://berdesa.com

Sanders, Patricia (1982). Phenomenology: A New Way of Viewing Organizational Research. Academy of Management Review. Vol. 7 (3) pp 353-360.

Sari Permata Yasmine. "Analisis Faktor Pembentukan Bumdes Pagedangan Cahaya Madani Dalam perspektif Governance". Departemen Administrasi Publik Fakultas Ilmu Sosial dan Ilmu Politik Universitas Diponegoro.

Sumaryadi Nyoman I \& Saputra Romi. “ The Role of The Village Business Agency As Creative Economic Implementation in Order of Community Empowerment of Villages of Cagak Road Subang District West Java Province". International Journal of Information Technomogy and Businness Management. ISSN 2304 - 0777. www.jitbm.com. Vol.58 No.1. $15^{\text {th }}$ Dec 2017.

Syncore, R (2017, April 16). 10 Titik Kritis BUMDes, Dipetik dari bumdes.id: http://bumdes.id/blog/2017/04/16/10-titik-kritis-bumdes/

Undang - Undang Nomor 32 Tahun 2004 tentang Pemerintahan Daerah

Undang - Undang Nomor 6 Tahun 2014 tentang Desa

World Bank. (1998). "The Initiative on Difining, Monitoring and Measuring Social Capital: Text of Proposal Approved for Funding”. Social Capital Initiative Working Paper No.2. The World Bank, Social Development Family, Enviromentally and Socially Sustainable $\begin{array}{llll}\text { Development } & \text { Network. } & \text { June } & 1998 .\end{array}$ http://www1.worldbank.org/prem/poverty/scapital/wkrppr/sciwp2.pdf. 9 mei 2005).

Yudiardi Dodi dan Karlina Nina (2017). "Identification of Supporting and Inhibiting Factors of Bumdes (Village - Owned Enterprises) Village Development Planning in Sukarame District Garut". Global Journal of Politic and Law Research Vol.5 No.1, pp.1-14 February 2017. Published by European Centre for Research Training and Development UK (www.eajournals.org). 